\title{
Mortality Risk Factors among Hospitalized COVID-19 Patients in a Major Referral Center in Iran
}

\author{
Nasser Malekpour Alamdari, ${ }^{1, *}$ Siamak Afaghi, ${ }^{2, *}$ Fatemeh Sadat Rahimi, ${ }^{2, *}$ \\ Farzad Esmaeili Tarki, ${ }^{2, *}$ Sasan Tavana, ${ }^{3}$ Alireza Zali, ${ }^{4}$ Mohammad Fathi, ${ }^{5}$ \\ Sara Besharat, ${ }^{6}$ Leyla Bagheri, ${ }^{2}$ Fatemeh Pourmotahari, ${ }^{6}$ \\ Seyed Sina Naghibi Irvani, ${ }^{7}$ Ali Dabbagh ${ }^{8}$ and Seyed Ali Mousavi ${ }^{9}$

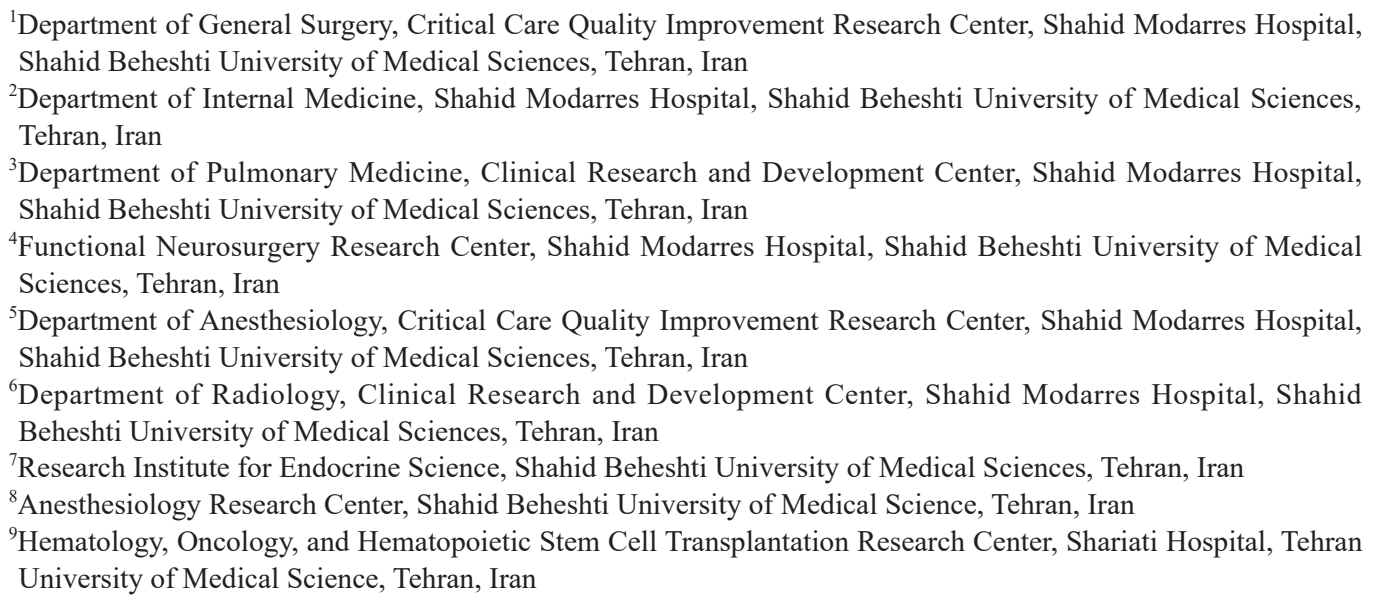

The Coronavirus Disease 2019 (COVID-19) pandemic has killed many people worldwide since December 2019, and Iran has been among the most affected countries. In this retrospective study, we aimed to determine the prognostic factors associated with mortality in COVID-19 patients by analyzing 396 survived and 63 non-survived patients in Shahid Modarres Hospital, Tehran, Iran, from January $30^{\text {th }}$ until April $5^{\text {th }}$, 2020. As the results, the BMI $>35(p=0.0003)$, lung cancer $(p=0.007)$, chronic kidney disease $(p=$ $0.002)$, Immunocompromised condition $(p=0.003)$, and diabetes $(p=0.018)$ were more frequently observed in the expired group. The history of statins use was more common in the discharged group $(p=$ 0.002), while there was no significant difference in the drug history of angiotensin-converting enzyme inhibitors, angiotensin II receptor blockers, nonsteroidal anti-inflammatory drugs, aspirin, and/or steroids, and in the past-year influenza vaccination. Multivariable regression demonstrated rising odds of in-hospital death related with age (odds ratio $(O R)=1.055, p=0.002)$, levels of C-reactive protein $(C R P)(O R=2.915$, $p<0.001)$, creatinine (OR $=1.740, p=0.023)$, lymphocyte count $(O R=0.999, p=0.008)$, and magnesium level $(\mathrm{OR}=0.032, \mathrm{p}<0.001)$ on admission. In conclusion, the patients with older age and higher BMI with lymphopenia, hypomagnesemia, elevated CRP and/or raised creatinine on admission are at higher risk of mortality due to the COVID-19 infection, which requires the physicians to use timely and strong therapeutic measures for such patients.

Keywords: COVID-19; Iran; prognosis; risk factor; SARS-CoV-2

Tohoku J. Exp. Med., 2020 September, 252 (1), 73-84.

Received May 7, 2020; revised and accepted July 27, 2020. Published online September 9, 2020; doi: 10.1620/tjem.252.73.

Correspondence: Seyed Sina Naghibi Irvani, M.D., M.P.H., M.B.A., Research Institute for Endocrine Science, Shahid Beheshti University of Medical Sciences, Arabi Ave, Velenjak, Tehran 19857-17443, Iran.

e-mail: sina.irvani@gmail.com

*These authors contributed equally to this study.

(C)2020 Tohoku University Medical Press. This is an open-access article distributed under the terms of the Creative Commons Attribution-NonCommercial-NoDerivatives 4.0 International License (CC-BY-NC-ND 4.0). Anyone may download, reuse, copy, reprint, or distribute the article without modifications or adaptations for non-profit purposes if they cite the original authors and source properly.

https://creativecommons.org/licenses/by-nc-nd/4.0/ 


\section{Introduction}

Back in December 2019, a considerable number of individuals diagnosed with pneumonia of a non-identified cause started to appear in Wuhan City, Hubei Province, China (Mackenzie and Smith 2020). It was delineated that this pneumonia has been provoked by Severe Acute Respiratory Syndrome Coronavirus 2 (SARS-CoV-2), one of the Coronavirus family members (Yang and Wang 2020). The low severity of disease in the initial stage and the long incubation period have been the main explanations for the very rapid patient outbreak. Being a potential worldwide threat, Coronavirus Disease 2019 (COVID-19) was proclaimed a public health crisis as well as a pandemic by the World Health Organization (WHO) (Cucinotta and Vanelli 2020). In the past two decades, Middle East Respiratory Syndrome (MERS) and Severe Acute Respiratory Syndrome (SARS), two antecedent deadly subtypes of Coronaviruses, were discovered to cause respiratory disease in human and animal hosts, with a death toll of 858 and 774, respectively (de Wit et al. 2016). Almost every country has been affected by the COVID-19 disaster. The number of afflicted patients has exceeded 2.8 million globally at the time of writing this article, and by 27th April 2020, the overall death toll in all nations has surpassed 198 thousand (WHO, World Health Organization 2020b). Iran is among the most considerably affected countries so far, in which the absence of published data on its patients has been profoundly felt among the scientific society. In consideration of the foregoing, the goal of this research was to detail the epidemiologic findings, clinical manifestation, and laboratory features, along with therapeutic and prognostic characteristics of admitted patients with COVID-19 in Tehran, Iran. It is anticipated that these results will assist the global community to apprehend this novel disease better and to treat it successfully, through evaluating COVID-19-related prognostic factors.

\section{Methods}

\section{Study design}

The current retrospective cross-sectional large-scale research, was performed from January $30^{\text {th }}$ to April $5^{\text {th }}$, 2020, on COVID-19 patients who were admitted to Shahid Modarres Hospital, which is a 279-bed tertiary referral center in Tehran, Iran, with four active ICU's including 70 beds combined. Throughout the primary disease surge, about $70 \%$ of the total hospital beds were dedicated to COVID-19 patients. All the patients enrolled in the study were admitted after being matched with WHO confirmation guidelines (WHO 2020a). The research protocol was fully assessed and approval by the Ethics Committee, Deputy of Research, Shahid Beheshti University of Medical Sciences, Tehran, Iran. All steps of the study followed the ethics criteria of the latter ethics body, including taking informed written patient consents (ethics approval code: IR.SBMU. RETECH.REC.1399.049)

\section{Patients}

The process of clinical assessment and hospital admission for all suspected COVID-19 patient was based on definite clinical and para-clinical features. The patient flow started in the emergency department; where the patients were screened by the medical staff immediately, and afterwards, they were taken to a specific part of emergency department passing a specifically designed route. Then nasopharyngeal sampling for Reverse TranscriptasePolymerase Chain Reaction (RT-PCR) was performed as the verifying test for diagnosis of all suspected patients.

In the next step, a thorough and extensive assessment was performed using a standard clinical checklist which was based on the "National Iranian Covid-19 Guideline (Abdi 2020); the latter guideline included the clinical presentations (i.e., vital signs, the level of oxygen saturation, etc.) and computerized tomographic scanning (CT scan) for assessing the radiologic features. Then, it was determined whether each individual patient should be treated as an outpatient, or be admitted and treated through inpatient care. The personal protection protocols were strictly adhered in order to prevent airborne viral spread throughout the hospital, including protection equipment and patient transfer through designed isolated physical pathway in the hospital. Also, as an additional precautionary measure, they were given fit-tested unfiltered surgical masks. We included 459 admitted patients who in the end, had a determined status of either being expired $(n=63)$ or discharged $(n=396)$. Those patients being still hospitalized till the last day of the study were excluded from the study population.

\section{Data collection}

Epidemiological and clinical findings, laboratory features, as well as therapeutic characteristics, were all procured using valid and reliable data collection forms from electronic health records. In order to improve validity and reliability, data collection forms were re-evaluated by three researchers separately, double-checking the accuracy of the extracted data. To ensure that the data of all patients have been gathered, the clinical and epidemiological information of the cases who didn't have available electronic medical records were also acquired. For doing so, the patients or their family members were communicated directly by the research team.

\section{Statistical analysis}

Categorical and continuous variables have been respectively described as $\mathrm{n}[\%]$ and mean \pm standard deviation (SD). Chi-squared test, Mann-Whitney test, and Fisher's exact test have been taken into use to collate contrasts between the expired and discharged groups wherever it suited. For investigating the risk factors related to deaths within the hospital, univariable and multivariable logistic regression models have been utilized. To prevent overfitting within the model, six variables have been selected for multivariable analysis based on clinical constraints and pre- 
vious findings, particularly considering the death toll $(\mathrm{n}=$ 63 ) in our research. Multi-collinearity was checked in the model; all variables had Variance Inflation Factor well below 2. The Hosmer-Lemeshow test was used to evaluate the quality of the fit for the multivariable logistic regression. Given the special attention paid to the age and lymphocyte count in previous studies, we decided to consider them as well (Zhou et al. 2020). Creatinine and C-reactive Protein (CRP), being the two most available laboratory tests, were utilized for further analysis of the results in this study. Of note, the present malignancy and magnesium $(\mathrm{Mg})$ blood levels were considered for assessment because of the statistically significant difference that they had made, and also because they were less contemplated in the past researches. Hence, lymphocyte count, CRP, Creatinine, $\mathrm{Mg}$, age, and the present malignancy were the six variables picked for the multivariable logistic regression model. A two-sided $\alpha$ less than 0.05 was deemed as statistically significant. The statistical examinations have been carried out using the R software (version: 3.6.3) and the IBM SPSS statistics (version: 26.0).

\section{Results}

As shown in Table.1, the average age in the expired group was significantly higher compared to the discharged group (70.58 \pm 10.66 vs. $60.39 \pm 11.47 ; \mathrm{p}<0.001)$; and in total, the men were hospitalized more often than women (69.7\% vs. $30.3 \%$ ). The blood type A had the highest prevalence in both expired (39.7\%) and discharged groups (37.4\%). In the two cohorts, the blood groups $\mathrm{O}, \mathrm{B}$, and $\mathrm{AB}$ were the next ones in the order of prevalence. $17.46 \%$ of the expired patients claimed that they have had recent close contact with a confirmed COVID-19 patient, while $7.21 \%$ of the discharged group remembered this close contact history $(\mathrm{p}=0.006)$. History of past-year influenza vaccination was $5.3 \%$ in discharged and $1.6 \%$ in the expired group. The number of current smokers was $28 \%$ and $31.7 \%$ in discharged and expired groups, respectively, which showed no statistically significant difference $(p=0.544)$. Neither the average pack-year smoking $(p=0.313)$ nor opioid addiction status $(\mathrm{p}=0.264)$ had a significant difference between the two groups. Hypertensive disorders (46.6\%), coronary heart disease $(40.3 \%)$, and chronic obstructive respiratory disease $(28.8 \%)$ had the highest prevalence among all patients. The fatality rate has been markedly greater among patients suffered from the comorbidities like diabetes $(p=0.018)$, malignancy $(p=0.008)$, Chronic Kidney Disease $(\mathrm{CKD})(\mathrm{p}=0.002)$, and the Body Mass Index (BMI) more than $35(\mathrm{p}=0.0003)$. Lung cancer $(9.5 \%)$, prostate cancer $(6.3 \%)$, and breast cancer $(3.2 \%)$ were the most common types of cancers in the expired group. In contrast, prostate cancer $(4.5 \%)$ was the most prevalent malignancy in the discharged group, while lung $(2 \%)$ and breast $(2 \%)$ cancer were the next two most common malignancies. The prevalence of lung cancer was significantly greater in the expired group $(p=0.007)$, while there was not any statistically remarkable distinction in the prevalence of other types of malignancies like prostate ( = $0.524)$ and breast $(p=0.63)$ cancer between the two groups. Drug history of statin medication was reported notably more in discharged group in comparison with the expired group ( $28 \%$ vs. $9.5 \%, p=0.002)$; while there was no statistically significant difference regarding history of using steroid-derived medications $(\mathrm{p}=0.47)$, nonsteroidal antiinflammatory drugs (NSAIDs) $(\mathrm{p}=0.62)$, angiotensin II receptor blockers (ARBs) $(p=0.71)$, angiotensin-converting enzyme inhibitors $(\mathrm{ACEI})(\mathrm{p}=0.14)$, and aspirin $(\mathrm{p}=$ $0.52)$.

Table 2 indicates that shortness of breath (86.5\%), fever $(83.7 \%)$, myalgia (61.9\%), and cough $(54.7 \%)$ were the most common chief complaints of hospitalized patients, whereas hemoptysis $(1.5 \%)$, sneezing $(3.7 \%)$, rhinorrhea $(5.7 \%)$, and ageusia/dysgeusia (7\%) were the least common ones. Gastrointestinal presentations like vomiting, diarrhea, and abdominal pain were observed respectively in $32 \%$, $27.2 \%$, and $18.7 \%$ of all patients. Shortness of breath $(\mathrm{p}=$ $0.003)$ and hemoptysis $(p=0.008)$ has been reported considerably more in the expired group. Considering the vital signs, average body temperature in the expired group was $38.69( \pm 1.30)$, while this was found to be $38.05( \pm 1.18)$ among the discharged $(p=0.001)$. The percentage of the discharged group with a heart rate of $>90 / \mathrm{min}$ was $4.5 \%$, while that was $12.7 \%$ among the expired group, indicating a significant difference $(p=0.017)$. Moreover, the expired cohort had significantly lower oxygen saturation upon arrival to the hospital $(\mathrm{p} \leq 0.001)$.

Table 3 highlights that the laboratory findings of below-mentioned items, were significantly detected more in patients with the final status of death: 1$)$ increased alanine transaminase (ALT) $(\mathrm{p}=0.040)$, aspartate transaminase $($ AST $)(p=0.044)$, direct bilirubin $(p=0.046)$, and decreased albumin $(p=0.031)$ as liver function markers, 2$)$ increased creatinine $(p<0.001)$ and urea $(p=0.030)$ as Kidney function markers, 3) Increased number of White Blood Cells (WBC) $(p=0.001)$, neutrophil $(p<0.001)$, and platelet $(\mathrm{p}=0.003)$ as well as lymphopenia $(\mathrm{p}<0.001), 4)$ increased levels of CRP $(p<0.001)$, D-dimer $(p<0.001)$, Lactate Dehydrogenase (LDH) $(\mathrm{p}<0.001)$, and Partial Thrombin Time (PTT) $(\mathrm{p}=0.008)$, and 5) low potassium levels $(p=0.0002)$ and Mg levels $(p<0.0001)$ among electrolytes imbalances.

As delineated in Table 4, the average period from the onset of symptoms to hospital admission was $5.45( \pm 3.36)$ and $7.37( \pm 3.66)$ days among the discharged and the expired patients, respectively, which shows significant difference between the two groups $(p<0.0001)$. Also, the average days that the discharged group and the expired group stayed in ICU were $3.60( \pm 5.53)$ and $7.78( \pm 4.48)$, respectively $(\mathrm{p}<0.0001)$. In addition, the length of hospitalization time in the isolated respiratory ward, for the expired group was significantly lower $(\mathrm{p}<0.0001)$. For the sake of patients' safety, we had started oxygen-therapy for 
N.M. Alamdari et al.

Table 1. Demographic information, comorbidity, and drug history.

\begin{tabular}{|c|c|c|c|c|}
\hline & $\begin{array}{c}\text { Total } \\
(\mathrm{n}=459)\end{array}$ & $\begin{array}{l}\text { Discharged } \\
(\mathrm{n}=396)\end{array}$ & $\begin{array}{l}\text { Expired } \\
(\mathrm{n}=63)\end{array}$ & $\mathrm{p}$ value \\
\hline \multicolumn{5}{|c|}{ Primary information } \\
\hline Age $($ mean $\pm \mathrm{SD})$ & $\begin{array}{c}61.79 \pm 11.89 \\
\mathrm{n}[\%]\end{array}$ & $\begin{array}{c}60.39 \pm 11.47 \\
\mathrm{n}[\%]\end{array}$ & $\begin{array}{c}70.58 \pm 10.66 \\
\mathrm{n}[\%]\end{array}$ & $<0.0001^{*}$ \\
\hline Sex & -- & -- & -- & 0.134 \\
\hline Male & $320[69.7 \%]$ & $271[68.4 \%]$ & $49[77.8 \%]$ & \\
\hline Female & $139[30.3 \%]$ & $125[31.6 \%]$ & $14[22.7 \%]$ & \\
\hline Blood type & -- & -- & -- & 0.814 \\
\hline $\mathrm{O}$ & $145[31.6 \%]$ & $127[32.1 \%]$ & $18[28.6 \%]$ & \\
\hline A & $173[37.7 \%]$ & $148[37.4 \%]$ & $25[39.7 \%]$ & \\
\hline B & $95[20.7 \%]$ & $80[20.2 \%]$ & $15[23.8 \%]$ & \\
\hline $\mathrm{AB}$ & $46[10.0 \%]$ & $41[10.4 \%]$ & $5[7.9 \%]$ & \\
\hline History of close contact with COVID-19 patient & $39[\% 8.49]$ & $28[7.21 \%]$ & $11[17.46 \%]$ & $0.006^{*}$ \\
\hline Past-year influenza vaccine & $22[4.8 \%]$ & $21[5.3 \%]$ & $1[1.6 \%]$ & 0.338 \\
\hline Current smoker & $131[28.5 \%]$ & $111[28 \%]$ & $20[31.7 \%]$ & 0.544 \\
\hline Pack/year of smoking & $7.46 \pm 18.53$ & $6.91 \pm 18.22$ & $10.92 \pm 22.24$ & 0.313 \\
\hline Opioid addiction & $29[6.3 \%]$ & $23[5.8 \%]$ & $6[9.5 \%]$ & 0.264 \\
\hline \multicolumn{5}{|c|}{ Comorbidity } \\
\hline Body Mass Index $>35$ & $36[7.8 \%]$ & $23[5.8 \%]$ & $13[20.16 \%]$ & $0.0003 *$ \\
\hline Diabetes & 119 [25.19\%] & $95[24.0 \%]$ & $24[38.1 \%]$ & $0.018^{*}$ \\
\hline Hypertensive disorders & $214[46.6 \%]$ & $188[47.5 \%]$ & $26[41.3 \%]$ & 0.359 \\
\hline Coronary heart disease & $185[40.3 \%]$ & $156[39.4 \%]$ & $29[46 \%]$ & 0.318 \\
\hline Chronic kidney disease & $99[21.6 \%]$ & $76[19.2 \%]$ & $23[36.5 \%]$ & $0.002 *$ \\
\hline Chronic liver disease & $29[6.3 \%]$ & $24[6.1 \%]$ & $5[7.9 \%]$ & 0.576 \\
\hline Chronic obstructive respiratory disease & $32[28.8 \%]$ & $109[27.5 \%]$ & $23[36.5 \%]$ & 0.143 \\
\hline Malignancy & $52[11.3 \%]$ & $38[9.6 \%]$ & $14[22.2 \%]$ & $<0.008^{*}$ \\
\hline Prostate cancer & $22[4.8 \%]$ & $18[4.5 \%]$ & $4[6.3 \%]$ & 0.524 \\
\hline Lung cancer & $14[3.1 \%]$ & $8[2 \%]$ & $6[9.5 \%]$ & $0.007 *$ \\
\hline Breast cancer & $10[2.2 \%]$ & $8[2 \%]$ & $2[3.2 \%]$ & 0.63 \\
\hline Other cancers & $8[1.7 \%]$ & $6[1.5 \%]$ & $2[3.2 \%]$ & 0.302 \\
\hline Immunocompromised & $108[23.5 \%]$ & $84[21.2 \%]$ & $24[38.1 \%]$ & $0.003 *$ \\
\hline \multicolumn{5}{|c|}{ Drug history } \\
\hline Steroids & $80[17.4 \%]$ & $67[16.9 \%]$ & $13[20.6 \%]$ & 0.47 \\
\hline NSAIDs & $37[8.1 \%]$ & $31[7.8 \%]$ & $6[9.5 \%]$ & 0.62 \\
\hline $\mathrm{ARBs}$ & $78[17 \%]$ & $69[17.4 \%]$ & $9[14.3 \%]$ & 0.71 \\
\hline ACE Inhibitors & $56[12.2 \%]$ & $52[13.1 \%]$ & $4[6.3 \%]$ & 0.14 \\
\hline ASA & $53[11.5 \%]$ & $44[11.1 \%]$ & $9[14.3 \%]$ & 0.52 \\
\hline Statins & $117[25.5 \%]$ & $111[28 \%]$ & $6[9.5 \%]$ & $0.002 *$ \\
\hline
\end{tabular}

This table shows the demographic information, comorbidities, and drug history of all the patients. The results are expressed as the mean $\pm \mathrm{SD}$ or the number of cases, with percentages in the brackets.

$* \mathrm{p}<0.05$

all hospitalized patients. Of therapeutic considerations, Nasal cannula had been used in $59.8 \%$ of discharged patients and $12.7 \%$ of expired patients, showing how significantly more utilized was it, in the discharged group $(\mathrm{p}<$ $0.0001)$. On the other hand, non-invasive ventilation and invasive ventilation, both were used significantly more in the expired group, making a $\mathrm{p}$ value of less than 0.0001 for both of them. Amongst the different antiviral agents administrated, the only drug that showed a significant difference in the outcomes, was hydroxychloroquine. The expired cases had been administrated with the drug, significantly less than the discharged group $(85.7 \%$ vs. $94.2 \%$; $p=$ 0.028). ICU admission $(\mathrm{p}<0.001)$, Acute Respiratory Distress Syndrome (ARDS) $(\mathrm{p}<0.0001)$, acute liver failure 
Table 2. Clinical presentation and vital signs upon arrival at the hospital.

\begin{tabular}{|c|c|c|c|c|}
\hline & $\begin{array}{c}\text { Total } \\
(\mathrm{n}=459)\end{array}$ & $\begin{array}{c}\text { Discharged } \\
(\mathrm{n}=396)\end{array}$ & $\begin{array}{l}\text { Expired } \\
(\mathrm{n}=63)\end{array}$ & $\mathrm{p}$ value \\
\hline & $\mathrm{n}[\%]$ & $\mathrm{n}[\%]$ & $\mathrm{n}[\%]$ & \\
\hline \multicolumn{5}{|c|}{ Sign and symptoms } \\
\hline Shortness of breath & $397[86.5 \%]$ & $335[84.6 \%]$ & $62[98.4 \%]$ & $0.003 *$ \\
\hline Fever & $384[83.7 \%]$ & $326[82.3 \%]$ & $58[92.1 \%]$ & 0.052 \\
\hline myalgia & $284[61.9 \%]$ & $247[62.4 \%]$ & $37[58.7 \%]$ & 0.580 \\
\hline Cough & $251[54.7 \%]$ & $213[53.8 \%]$ & $38[60.3 \%]$ & 0.344 \\
\hline Sweating & $225[49.0 \%]$ & $194[48.9 \%]$ & $31[49.2 \%]$ & 0.975 \\
\hline Vomiting & $147[32.0 \%]$ & $128[32.3 \%]$ & 19 [30.2\%] & 0.732 \\
\hline Diarrhea & $125[27.2 \%]$ & $105[26.5 \%]$ & $20[31.7 \%]$ & 0.386 \\
\hline Sputum production & $94[20.5 \%]$ & $77[19.5 \%]$ & $17[27 \%]$ & 0.172 \\
\hline Headache & $89[19.4 \%]$ & 78 [19.7\%] & $11[17.5 \%]$ & 0.677 \\
\hline Abdominal pain & $86[18.7 \%]$ & $75[18.9 \%]$ & $11[17.5 \%]$ & 0.780 \\
\hline Anosmia & $48[10.5 \%]$ & $42[10.6 \%]$ & $6[9.5 \%]$ & 0.794 \\
\hline Ageusia & $32[7 \%]$ & $26[6.6 \%]$ & $6[9.5 \%]$ & 0.421 \\
\hline Runny nose & $26[5.7 \%]$ & $21[5.3 \%]$ & $5[7.9 \%]$ & 0.381 \\
\hline Sneeze & $17[3.7 \%]$ & $15[38.5 \%]$ & $2[3.2 \%]$ & 1.000 \\
\hline Hemoptysis & $7[1.5 \%]$ & $3[0.8 \%]$ & $4[6.3 \%]$ & $0.008^{*}$ \\
\hline \multicolumn{5}{|c|}{ Vital signs } \\
\hline & $\begin{array}{c}\text { Mean } \pm \text { SD } \\
\mathrm{n}[\%]\end{array}$ & $\begin{array}{c}\text { Mean } \pm \text { SD } \\
\mathrm{n}[\%]\end{array}$ & $\begin{array}{c}\text { Mean } \pm \mathrm{SD} \\
\mathrm{n}[\%]\end{array}$ & $\mathrm{p}$ value \\
\hline Temperature & $38.14 \pm 1.22$ & $38.05 \pm 1.18$ & $38.69 \pm 1.30$ & $0.001 *$ \\
\hline$\geq 37.3$ & $359[78.2 \%]$ & $301[76.0 \%]$ & $58[92.0 \%]$ & $0.004 *$ \\
\hline Heart rate & $79.10 \pm 5.94$ & $78.86 \pm 5.49$ & $80.59 \pm 8.15$ & 0.222 \\
\hline$\geq 90$ & $26[5.7 \%]$ & $18[4.5 \%]$ & $8[12.7 \%]$ & $0.017 *$ \\
\hline Respiratory rate & $21.54 \pm 3.05$ & $21.34 \pm 3.09$ & $22.75 \pm 2.43$ & $0.0001 *$ \\
\hline$>24$ & $82[17.9 \%]$ & $66[16.6 \%]$ & $14[22.2 \%]$ & 0.280 \\
\hline $\mathrm{O} 2$ saturation & $88.14 \pm 6.46$ & $89.05 \pm 5.46$ & $82.46 \pm 8.99$ & $<0.0001 *$ \\
\hline$<93$ & $378[82.4 \%]$ & $316[79.8 \%]$ & $62[98.4 \%]$ & $<0.0001 *$ \\
\hline Systolic blood pressure & $127.79 \pm 14.75$ & $127.65 \pm 15.39$ & $128.67 \pm 9.96$ & 0.265 \\
\hline Diastolic blood pressure & $84.18 \pm 9.20$ & $83.91 \pm 9.02$ & $85.86 \pm 10.23$ & 0.293 \\
\hline
\end{tabular}

This table shows the clinical presentations and vital signs of all the patients upon arrival at the hospital. The results are expressed as the mean $\pm \mathrm{SD}$ or the number of cases, with percentages in the brackets. $* \mathrm{p}<0.05$

( $p<0.0001)$, acute kidney injury $(\mathrm{p}<0.0001)$, and arrhythmia ( $p<0.0001)$ were described to be more prevalent complications during the hospitalization period among the expired group.

As shown in Table 5, amongst the six variables which had been selected for multivariable logistic regression model, the analyses of age $(\mathrm{OR}=1.055, \mathrm{p}=0.002), \mathrm{Mg}$ $(\mathrm{OR}=0.032, \mathrm{p}<0.0001)$, creatinine $(\mathrm{OR}=1.740, \mathrm{p}=$ $0.023)$, CRP (OR $=2.915, \mathrm{p}<0.0001)$, and lymphocytes $(\mathrm{OR}=0.999, \mathrm{p}=0.008)$ showed a statistically significant difference between the survivors and the non-survivors, whereas malignancy $(\mathrm{OR}=2.004, \mathrm{p}=0.104)$ was of no considerable difference.

Fig. 1 demonstrates the prevalence of sex in different age groups of expired and discharged patients, indicating that female patients are generally more likely to get well and be discharged compared with male patients. Additionally, a brief view can delineate the fact that how female is more common in all discharged group and almost all age ranges, especially in comparison with the expired group. However, as mentioned before, the univariate analysis did not show a statistically significant benefit of being female to avoid mortality.

\section{Discussion}

We carried out our retrospective research on a total of 459 confirmed COVID-19 patients consisting of 396 survivors and 63 non-survivors. As far as we know, this is the first-ever research to publish data on hospitalized COVID19 patients in Iran, particularly with this scale of the study 
Table 3. First laboratory findings upon admission to the hospital.

\begin{tabular}{|c|c|c|c|c|}
\hline \multirow[t]{2}{*}{ Laboratory finding (unit) } & $\begin{array}{l}\text { Discharged } \\
(\mathrm{n}=396)\end{array}$ & $\begin{array}{l}\text { Expired } \\
(\mathrm{n}=63)\end{array}$ & \multirow[t]{2}{*}{ Range of Normal Value } & \multirow[t]{2}{*}{$\mathrm{p}$ value } \\
\hline & Mean \pm SD & Mean \pm SD & & \\
\hline Sodium (me/L) & $138.58 \pm 4.71$ & $138.10 \pm 6.09$ & $135-145 \mathrm{me} / \mathrm{L}$ & 0.730 \\
\hline Potassium (mmol/L) & $3.95 \pm 0.60$ & $3.65 \pm 0.87$ & $3.6-5 \mathrm{mmol} / \mathrm{L}$ & $0.0002 *$ \\
\hline Calcium (mg/dL) & $8.78 \pm 0.48$ & $8.81 \pm 0.47$ & $8.5-10.1 \mathrm{mg} / \mathrm{dl}$ & 0.568 \\
\hline Magnesium (me/L) & $1.83 \pm 0.24$ & $1.61 \pm 0.19$ & $1.5-2.5 \mathrm{me} / \mathrm{L}$ & $<0.0001^{*}$ \\
\hline Phosphate (mg/dL) & $3.08 \pm 0.55$ & $2.85 \pm 0.79$ & $2.5-4.5 \mathrm{mg} / \mathrm{dL}$ & 0.055 \\
\hline ALT (units per liter of serum) & $26.33 \pm 9.45$ & $28.94 \pm 11.14$ & 7-45 units per liter & $0.040^{*}$ \\
\hline AST (units per liter of serum) & $28.53 \pm 9.54$ & $27.46 \pm 13.61$ & $10-40$ units per liter & $0.044 *$ \\
\hline Total bilirubin (mg/dl) & $1.71 \pm 0.46$ & $1.78 \pm 0.57$ & 0.1 to $1.2 \mathrm{mg} / \mathrm{dL}$ & 0.548 \\
\hline Direct bilirubin (mg/dl) & $0.51 \pm 0.39$ & $0.65 \pm 0.48$ & $<0.3 \mathrm{mg} / \mathrm{dL}$ & $0.046^{*}$ \\
\hline PT (seconds) & $13.04 \pm 2.51$ & $13.41 \pm 3.32$ & $11-13.5$ seconds & 0.695 \\
\hline PTT (seconds) & $51.053 \pm 8.67$ & $49.03 \pm 12.91$ & $60-70$ seconds & $0.008^{*}$ \\
\hline INR & $1.17 \pm 0.40$ & $1.27 \pm 0.56$ & $0.8-1.1$ & 0.493 \\
\hline Albumin (g/dL) & $3.69 \pm 1.06$ & $3.36 \pm 0.93$ & $3.4-5.2 \mathrm{~g} / \mathrm{dL}$ & $0.031^{*}$ \\
\hline Creatinine (mg/dL) & $1.68 \pm 0.62$ & $2.13 \pm 0.75$ & $\begin{array}{c}\text { male: } 0.6-1.2 \\
\text { female: } 0.5-1.1 \mathrm{mg} / \mathrm{dL}\end{array}$ & $<0.0001 *$ \\
\hline Urea $(\mathrm{mg} / \mathrm{dL})$ & $18.32 \pm 5.42$ & $20.07 \pm 6.11$ & $7-20 \mathrm{mg} / \mathrm{dL}$ & $0.030^{*}$ \\
\hline $\mathrm{LDH}(\mathrm{U} / \mathrm{L})$ & $257.74 \pm 32.55$ & $296.87 \pm 61.99$ & $140-280 \mathrm{U} / \mathrm{L}$ & $<0.0001 *$ \\
\hline D-Dimer $(\mathrm{mcg} / \mathrm{mL})$ & $1.78 \pm 2.14$ & $3.39 \pm 2.94$ & $<0.4 \mathrm{mcg} / \mathrm{mL}$ & $<0.0001^{*}$ \\
\hline $\operatorname{ESR}(\mathrm{mm} / \mathrm{hr})$. & $37.77 \pm 9.14$ & $40.95 \pm 12.39$ & $\begin{array}{c}\text { male: }<13 \\
\text { female: }<20 \mathrm{~mm} / \mathrm{hr} .\end{array}$ & 0.072 \\
\hline $\begin{array}{l}\text { Qualitative CRP } \\
\text { (numbers indicate "plus" amounts) }\end{array}$ & $1.56 \pm 0.81$ & $2.61 \pm 0.92$ & $\begin{array}{l}\text { Negative CRP is } \\
\text { considered as normal }\end{array}$ & $<0.0001^{*}$ \\
\hline Hemoglobin (g/dL) & $12.74 \pm 1.35$ & $12.46 \pm 1.86$ & $\begin{array}{c}\text { male: } 13.5-17.5 \\
\text { female: } 12.0-15.5 \mathrm{~g} / \mathrm{dL}\end{array}$ & 0.391 \\
\hline WBC (thousand/mcL) & $6.33 \pm 1.51$ & $7.21 \pm 2.22$ & 4-11 thousand/mcL & $0.0001 *$ \\
\hline Neutrophil (thousand/mcL) & $4.40 \pm 1.44$ & $5.58 \pm 1.74$ & $1.8-7.7$ thousand/mcL & $<0.0001 *$ \\
\hline Lymphocyte (thousand/mcL) & $1.36 \pm 0.43$ & $1.02 \pm 0.43$ & $1.5-4.8$ thousand $/ \mathrm{mcL}$ & $<0.0001 *$ \\
\hline Platelet (thousand/mcL) & $178.13 \pm 104.17$ & $192.27 \pm 54.91$ & $150-450$ thousand $/ \mathrm{mcL}$ & $0.003 *$ \\
\hline
\end{tabular}

This table shows the first laboratory findings of all the patients upon admission to the hospital. The results are expressed as the mean $\pm \mathrm{SD}$.

${ }^{*} \mathrm{p}<0.05$

population, and this extent of inclusivity of all potential prognostic factors. Overall, multiple factors were found to have a significant effect on mortality among hospitalized patients. To be specific, we illustrated that elderly, patients with hypomagnesemia or increased levels of CRP and creatinine, along with low lymphocytes, encountered higher odds of fatality among hospitalized patients.

\section{Patients' characteristics}

We have found out in the present research that increased age was related to higher mortality in COVID-19 patients. Comparable to our results a study on SARSCoV-2 patients has shown that being of older age can contribute to a poor prognosis (with an Odds Ratio of 1.10) (Zhou et al. 2020). Older age has also been formerly recorded as a significant, independent mortality indicator in MERS and SARS (Jia et al. 2009; Hong et al. 2018). It would seem that the age-dependent deficiencies in the activ- ity of B-cell and T-cell, along with the surplus development of Type 2 cytokines may contribute to the defected control of viral replication along with more sustained inflammatory reactions, possibly taking an active role in the poor outcomes.

In line with a previous study (Jin et al. 2020), the mortality rate amongst the male population was more than three times greater than that of the female population (Fig. 1). It is believed that women are usually less vulnerable to viral diseases, probably due to the specific innate immunity mechanisms, steroidal hormones, and sex chromosomerelated causes. For the female individuals, the existence of two $\mathrm{X}$ chromosomes affects the immune response even though one is not active (Conti and Younes 2020).

One of the salient findings in the present study was that blood type A had a greater distribution in the expired groups and generally in all affected cases. Based on the epidemiologic study on the prevalence of different blood 
Table 4. Therapies and outcomes.

\begin{tabular}{|c|c|c|c|c|}
\hline & $\begin{array}{c}\text { Total } \\
(\mathrm{n}=459)\end{array}$ & $\begin{array}{l}\text { Discharged } \\
(\mathrm{n}=396)\end{array}$ & $\begin{array}{l}\text { Expired } \\
(\mathrm{n}=63)\end{array}$ & $\mathrm{p}$ value \\
\hline & Mean \pm SD & Mean \pm SD & Mean \pm SD & \\
\hline Days from illness onset to admission & $5.72 \pm 3.46$ & $5.46 \pm 3.36$ & $7.37 \pm 3.66$ & $<0.0001 *$ \\
\hline Days of being admitted to resp. ward & $3.61 \pm 3.42$ & $3.95 \pm 3.42$ & $1.44 \pm 2.51$ & $<0.0001^{*}$ \\
\hline Days of being admitted to ICU & $4.17 \pm 5.58$ & $3.60 \pm 5.53$ & $7.78 \pm 4.48$ & $<0.0001 *$ \\
\hline \multicolumn{5}{|c|}{ Oxygen therapy } \\
\hline & $\mathrm{n}[\%]$ & $\mathrm{n}[\%]$ & $\mathrm{n}[\%]$ & \\
\hline Nasal cannula & $245[53.4 \%]$ & $237[59.8 \%]$ & $8[12.7 \%]$ & $<0.0001 *$ \\
\hline None-invasive ventilation & $295[64.3 \%]$ & $237[59.8 \%]$ & $58[92.1 \%]$ & $<0.0001^{*}$ \\
\hline Invasive ventilation & $46[10.0 \%]$ & $28[7.1 \%]$ & $18[28.6 \%]$ & $<0.0001 *$ \\
\hline \multicolumn{5}{|c|}{ Antivirals } \\
\hline Oseltamivir & $247[53.8 \%]$ & $210[53.0 \%]$ & $37[58.7 \%]$ & 0.399 \\
\hline Lopinavir/Ritonavir (Kaletra) & $363[79.1 \%]$ & $311[78.5 \%]$ & $52[82.5 \%]$ & 0.616 \\
\hline Ribavirin & $25[5.4 \%]$ & $23[5.8 \%]$ & $2[3.2 \%]$ & 0.555 \\
\hline Hydroxychloroquine & $427[93.0 \%]$ & $373[94.2 \%]$ & $54[85.7 \%]$ & $0.028 *$ \\
\hline \multicolumn{5}{|c|}{ Complications during the admission } \\
\hline ICU admission & $215[46.84 \%]$ & $155[39.1 \%]$ & $60[95.2 \%]$ & $<0.001^{*}$ \\
\hline ARDS & $94[20.5 \%]$ & $37[9.3 \%]$ & $57[90.5 \%]$ & $<0.0001^{*}$ \\
\hline Acute liver failure & $84[18.3 \%]$ & $36[9.1 \%]$ & $48[76.2 \%]$ & $<0.0001^{*}$ \\
\hline Acute kidney injury & $128[27.9 \%]$ & $78[19.7 \%]$ & $50[79.4 \%]$ & $<0.0001^{*}$ \\
\hline Arrhythmia & $53[11.5 \%]$ & $23[5.8 \%]$ & $30[47.6 \%]$ & $<0.0001 *$ \\
\hline Secondary infection & $46[10.0 \%]$ & $39[9.8 \%]$ & $7[11.1 \%]$ & 0.757 \\
\hline
\end{tabular}

This table shows the therapies and reported outcomes of all patients. The results are expressed as the mean \pm SD or the number of cases, with percentages in the brackets. $* \mathrm{p}<0.05$

groups in Iran, blood group $\mathrm{O}$ as the most prevalent one in the general population has a $36.49 \%$ prevalence, and blood group A has a $32.09 \%$ prevalence; in contrast, in our study blood group $\mathrm{A}$, is the foremost prevalent one, highlighting a significant difference compared to what is observed in the general population. The prevalence of the other two blood groups $(\mathrm{B}$ and $\mathrm{AB})$ in the general population are respectively $23.68 \%$ and $7.74 \%$ (Shahverdi et al. 2016). These results are somehow in line with an article stating that patients with type A blood group, particularly those that have already been diagnosed with cardiovascular disease, have been more prone to experience severe courses of COVID-19 infection (Dai 2020). If it is determined that O-glycosylation has a major role in coronavirus infection, as previously stated for the SARS-CoV- 1 and is presently again speculated for SARS-CoV-2, this will entail the development of hybrid, serologically A-like antigenic complexes (Oostra et al. 2006).

In our research, having a history of close interaction with COVID-19 cases has dramatically raised the fatality risk in our sample. One possible reason may be the risk of spreading a larger load of the virus via direct interaction with mucosal fluids while sneezing or coughing, compared to the indirect transmission of the virus e.g., from the contaminated surfaces.

Similar to our findings, a meta-analysis on 1,399 COVID-19 patients in a Chinese population showed that current smoking status is not associated with an increased risk of adverse prognoses in COVID-19 patients (Lippi and Henry 2020). Moreover, we found that the history of opium abuse does not seem to raise the mortality risk in a statistically significant way. Despite that, we did witness clinically that opium abusers, especially those with serious substance dependence, dealt with lots of complications. It has been shown that opium receptors have gained extraordinary recognition as they can change the immune system, albeit obscurely, influencing the development of infectious diseases (Plein and Rittner 2018) and having impacts on viral replication (Salimi et al. 2013). Given the foregoing, these receptors might play a considerable part in the progression of COVID-19.

\section{Clinical manifestations}

In terms of evaluating clinical manifestations, hemoptysis as an atypical presentation was meaningfully related to death in our patients. As a common feature in many 
Table 5. Prognostic factors related to fatality in hospitalized COVID-19 patients.

The Hosmer-Lemeshow test: $\chi^{2}=6.40, p=0.602$.

\begin{tabular}{|c|c|c|c|c|}
\hline & Univariable OR $(95 \% \mathrm{CI})$ & $\mathrm{p}$ value & multivariable OR $(95 \% \mathrm{CI})$ & $\mathrm{p}$ value \\
\hline \multicolumn{5}{|c|}{ DEMOGRAPHICS AND CLINICAL CHARACTERISTICS } \\
\hline Age, years & $1.085(1.056-1.114)$ & $<0.0001 *$ & $1.055(1.019-1.091)$ & $0.002 *$ \\
\hline Female sex (vs. male) & $0.619(0.330-1.164)$ & 0.137 & .. &.. \\
\hline BMI more than 35 (vs. BMI less than 35) & $4.217(2.009-8.850)$ & $<0.0001^{*}$ & .. & .. \\
\hline Current Smoker (vs. non-smoker) & $1.194(0.673-2.120)$ & 0.544 & .. & .. \\
\hline \multicolumn{5}{|l|}{ Comorbidity present (vs. not present) } \\
\hline Diabetes Mellitus & $1.95(1.116-3.408)$ & $0.019 *$ & .. & .. \\
\hline Chronic Kidney Disease & $2.421(1.368-4.284)$ & $0.002 *$ &.. & .. \\
\hline Malignancy & $3.482(1.819-6.663)$ & $<0.0001 *$ & $2.004(0.867-4.630)$ & 0.104 \\
\hline Immunocompromised & $2.286(1.302-4.012)$ & $0.004 *$ & .. &.. \\
\hline \multicolumn{5}{|l|}{ Vital signs } \\
\hline $\mathrm{O}_{2}$ Sat & $0.887(0.851-0.925)$ & $<0.0001^{*}$ &.. &.. \\
\hline Respiratory Rate & $1.429(0.746-2.737)$ & 0.282 & .. & .. \\
\hline Temperature $>37.3$ & $3.661(1.427-9.393)$ & $0.007 *$ & .. & .. \\
\hline
\end{tabular}

LABORATORY FINDINGS

\begin{tabular}{|c|c|c|c|c|}
\hline \multicolumn{5}{|l|}{ Electrolytes } \\
\hline K & $0.501(0.334-0.751)$ & $0.001^{*}$ & .. & .. \\
\hline $\mathrm{Mg}$ & $0.011(0.003-0.044)$ & $<0.0001^{*}$ & $0.032(0.007-0.136)$ & $<0.0001 *$ \\
\hline \multicolumn{5}{|l|}{ Liver function test (LFT) } \\
\hline ALT & $1.023(0.999-1.047)$ & 0.060 & .. & .. \\
\hline AST & $0.988(0.957-1.019)$ & 0.440 & .. & .. \\
\hline PTT & $0.976(0.948-1.006)$ & 0.112 & .. & .. \\
\hline Albumin & $0.735(0.563-0.960)$ & $0.024 *$ & .. & .. \\
\hline Direct Bilirubin & $2.101(1.162-3.796)$ & $0.014 *$ & .. & .. \\
\hline Indirect Bilirubin & $0.447(0.181-1.102)$ & 0.080 & .. & .. \\
\hline Lactate dehydrogenase & $1.028(1.019-1.037)$ & $<0.0001 *$ & .. & .. \\
\hline \multicolumn{5}{|l|}{ Kidney function test (KFT) } \\
\hline Creatinine & $2.308(1.587-3.356)$ & $<0.0001 *$ & $1.740(1.080-2.803)$ & $0.023 *$ \\
\hline Blood Urea Nitrogen & $1.050(1.007-1.095)$ & $0.023 *$ & .. &.. \\
\hline \multicolumn{5}{|l|}{ Other lab findings } \\
\hline WBC Count & $1.000(1.000-1.000)$ & $<0.0001^{*}$ & .. & .. \\
\hline Lymphocytes Count & $0.998(0.997-0.999)$ & $<0.0001 *$ & $0.999(0.998-1.000)$ & $0.008^{*}$ \\
\hline Neutrophils Count & $1.000(1.000-1.001)$ & $<0.0001 *$ & .. &.. \\
\hline Platelets Count & $1.000(1.000-1.000)$ & 0.296 & .. & .. \\
\hline D-dimer & $1.259(1.144-1.386)$ & $<0.0001 *$ & .. & .. \\
\hline C-Reactive Protein & $3.843(2.708-5.454)$ & $<0.0001^{*}$ & $2.915(1.958-4.339)$ & $<0.0001 *$ \\
\hline
\end{tabular}

This table shows the logistic regression for univariable and multivariable analysis, indicating the prognostic factors related to fatality in hospitalized COVID-19 patients (with the Hosmer-Lemeshow test: $\chi^{2}=6.40, \mathrm{p}$ value $=0.602$ ). The results are expressed as the Odds Ratio numbers with Confidence Interval in the parentheses. $* \mathrm{p}<0.05$

patients, hemoptysis may be attributed to a rare complication of pulmonary embolism induced by COVID-19 (Casey et al. 2020). However, more studies are needed to confirm these claims.

Of note, we found anosmia/hyposmia and ageusia/dysgeusia in $10.5 \%$ and $7.5 \%$ of all patients, respectively. A relevant study has shown that losing sense of smell and taste in patients with the influenza-like syndrome presenta- tions, strongly supports the possibility of SARS-CoV-2. Notwithstanding, the prevalence of anosmia/hyposmia and ageusia/dysgeusia in that study was $68 \%$ and $71 \%$ respectively among COVID-19 patients, which overall was much more common than what we found in our study, probably due to the retrospective nature of our study (Yan et al. 2020). 


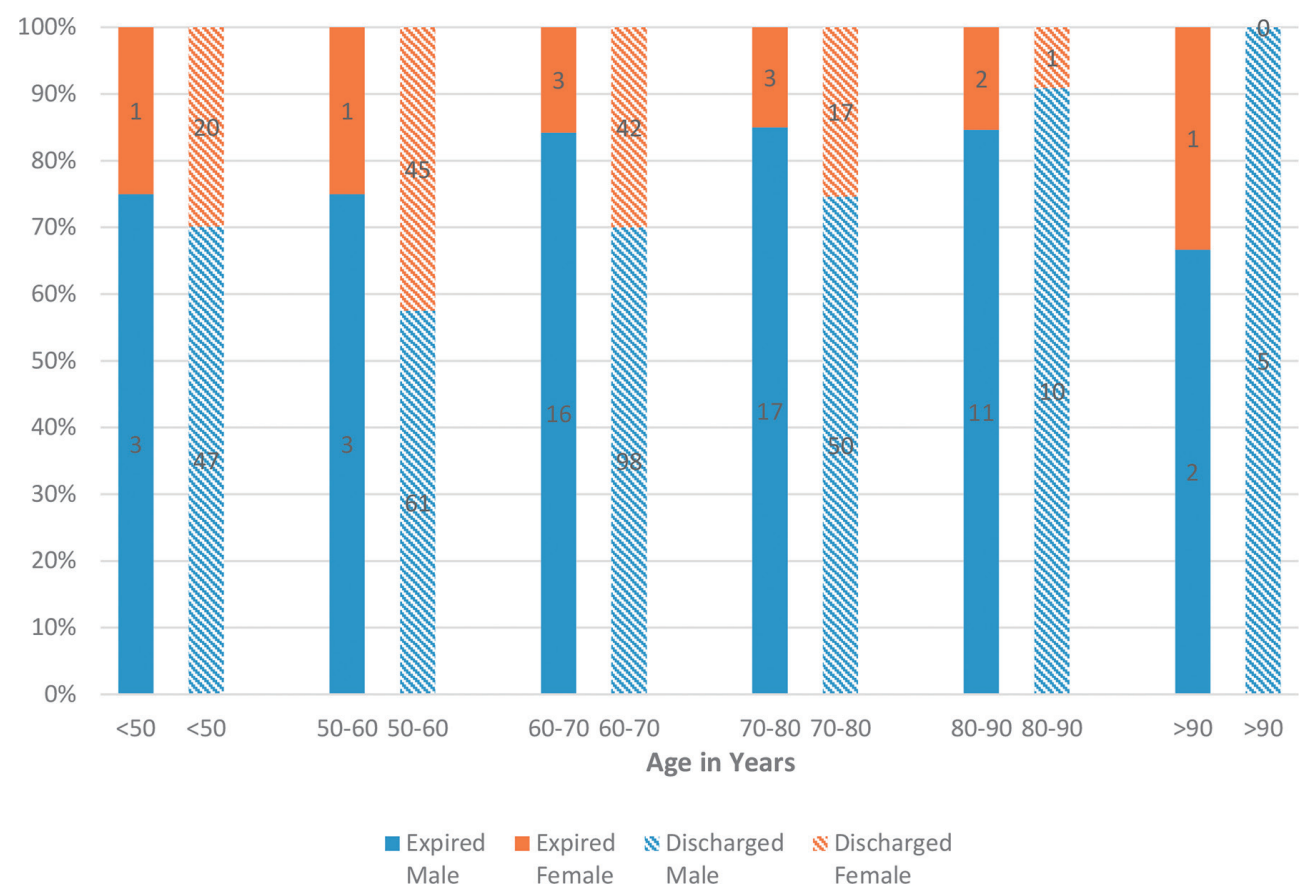

Fig. 1. Comparison of sex in age categories of expired and discharged COVID-19 patients.

This figure demonstrates the comparison of sex in age categories of expired and discharged COVID-19 patients.

\section{Comorbidities}

We also revealed that there's a significantly higher prevalence of obesity, defined as a BMI of 35 or higher, in the confirmed COVID-19 in-hospital expired cases. Surprisingly, despite the climbing burden of obesity worldwide, higher BMI has been rarely stated as a risk factor for death, among the early COVID-19 clinical reports (Grasselli et al. 2020; Holshue et al. 2020; Li et al. 2020). In concordance with our results, the research conducted in France found that the proportion of patients needing invasive mechanical ventilation has risen with BMI elevation (Simonnet et al. 2020). Based on the analyses, we concluded, that diabetes has been a comorbidity with a substantial link to COVID-19 mortality. Similar findings have been seen in patients with diabetes who had been involved with SARS and MERS (Yang et al. 2006; Alraddadi et al. 2016). It has also been shown that exposure of the respiratory epithelium cells to high glucose concentrations considerably enhances the infection rate and the replication of the influenza virus (Hulme et al. 2017).

Malignancy was also linked to a significant risk of death in our study. Actually, from our practical experience, essential medical services during this outbreak were not readily accessible for cancer patients, whether it was associated with being able to get to medical centers or providing standard medical services within hospitals. A new study on the potential possibility of lethal COVID-19 in malignancy patients has suggested that the handful of patients who were re-admitted, tended to have other recognizable risk factors for severe illness, rather than the malignancy-specific causes (Wang and Zhang 2020). In other words, patients with malignancy cannot be precisely evaluated and properly assessed, due to the complicated conditions caused by the malignancy, and the coexisting states of chemotherapy and/ or radiotherapy.

In our evaluation, we could indicate that the immunocompromised condition was a remarkable risk factor for fatality. Although, re-assessing the morbidity and mortality accounts released on MERS, SARS, and lately on COVID19 showed that there is no implication of immunodeficiency as a risk factor associated with death. Also, there is no record of higher mortality related to chemotherapy, transplantation, or other disorders that need immunosuppressant therapy at any age (Hui et al. 2018; D’Antiga 2020). Of note, regarding immunodeficiency status as a comorbidity with a strong association to a poor prognosis in COVID-19, unfavorable reactions in patients receiving immune checkpoints inhibitors are more challenging to detect, and may not be handled appropriately, which could, in turn, impair their survival.

We were also able to identify a link between CKD and death in our analyses. In a previous comparison, the pneumonia-related mortality risk in CKD cases, by and large, tends to be 14-16 times higher than in the general population (Sarnak and Jaber 2001). Regarding COVID-19, this may be clarified by the fact that SARS-CoV-2 similar to SARS-CoV-1 interacts via ACE2 with Renin-AngiotensinAldosterone System (RAAS) (Lippi and Henry 2020). ACE2, as an enzyme that normally counteracts the stimulation of RAAS, also takes part as a receptor for both types of SARS virus. Given that there are large amounts of ACE2 receptors in the kidneys and the lungs, COVID-19 may take the kidney as another significant target. 


\section{Drug usage}

As much as we could discover, this is the first retrospective cohort analysis of COVID-19 cases, which made an effort to complete a thoroughly rigorous history of drug usage and also to pinpoint comprehensive background of any form of opioid abuse. We also have unraveled that the prolonged period of days from the first symptom to the hospital admission, has led to an elevated risk of mortality in COVID-19 cases. Furthermore, statin use history decreased the incidence of mortality dramatically. Bearing in mind that statins have an immunomodulatory role and can reduce the risk of atherosclerosis as a cardiovascular risk factor, the need for broader research on this specific topic is much felt (Yuan 2015). Finally, we showed that the history of past-year influenza vaccination, and the background of using NSAIDs, ARBs, and ACEIs had no substantial impact on mortality.

\section{Laboratory findings}

As we have seen, the levels of potassium were markedly declined in the expired cohort. Hypokalemia is a wellrecognized risk factor for Ventricular Tachycardia, a common type of arrhythmia we found in COVID-19 patients (Helfant 1986). While evaluating the hypokalemic COVID-19 cases in our study, we noticed that the correction of potassium levels was difficult due to persistent kidney failure induced by ACE2 depletion.

In addition to potassium, imbalanced levels of $\mathrm{Mg}$ were shown to be a deciding factor of mortality in COVID19 cases. However, the rationale behind this phenomenon in COVID-19 cases is yet to be understood. A possible justification for this might be the fact that hypomagnesemia was a relatively common finding within the urban population of Iran, which has been demonstrated in an previous study (Syedmoradi et al. 2011). Hypomagnesemia was also reportedly correlated with an elevated mortality risk for both ward and surgical ICU patients (Rubeiz et al. 1993). Critically sick patients encounter many possible occasions where $\mathrm{Mg}$ levels are dysregulated. This may be attributed to gastrointestinal failure, diuretic renal waste or renal tubular disease, or sequestration in tissues.

We also discovered that the critical cases faced a greater risk of an ALT rise and an AST rise relative to noncritical cases. One of the largest longitudinal studies in China that enrolled 1,099 COVID-19 cases showed that the rise in average ALT and AST levels occurred in $21.3 \%$, and $22.2 \%$ of patients, respectively, being specifically higher in the critical patients (Guan et al. 2020). Moreover, we deduced that the low albumin level was directly associated with the death of COVID-19 cases. Lack of albumin is shown to be a risk factor for severe infection and adverse prognosis (Goldwasser and Feldman 1997).

In our investigation, an increase in total WBC count, neutrophils, and platelets alongside a decrease in lymphocytes were revealed to be significant prognostic predictor of the disease. Elevated platelet counts, as a criterion for inflammation, may suggest inflammatory processes in fatal patients compared to others. On the other hand, different count of neutrophils may denote the sepsis or secondary infections in the mortality group. Accordingly, declined levels of lymphocytes among COVID-19 patients have also been a reliable indicator of poor prognosis, reported in some other studies (Huang et al. 2020; Zhou et al. 2020).

We also brought this fact to light, that high levels of d-dimer are correlated with COVID-19 fatality. Around $90 \%$ of patients with pneumonia have been found to have elevated coagulative functions, pointed out by higher concentrations of d-dimer (Milbrandt et al. 2009). The related research has pointed out that the d-dimer of more than 1.0 $\mathrm{g} / \mathrm{mL}$ can be an indicator of adverse prognosis, which is in line with our results (Zhou et al. 2020). However, we could not determine any specific cut-off level for d-dimer's significance. Instead, we emphasized on the mere rise of d-dimer as an indicator of poor prognosis. In cases with an infection or sepsis diagnosed in the emergency room, elevated d-dimer has a confirmed correlation with 28-day mortality (Rodelo et al. 2012).

\section{Treatments}

Supportive care and oxygen therapy have been the cruces of treatment for COVID-19 patients. It is shown that severe infection with influenza virus and elongated viral shedding has been related to lethal outcomes. also, overdue antiviral therapy has been a separate risk factor for sustained detection of the virus in the specimens (Duwe 2017). Likewise, it was expected that successful antiviral therapy might enhance COVID-19 outcomes. Therefore, we attempted to analyze various types of antiviral agents based on the outcomes of our patients. As a result, we realized that reduced hydroxychloroquine administration has been significantly linked to mortality in our research. However, it is yet to be determined explicitly whether this noteworthy difference is due to the efficacy of the drug, or the mere comorbidities such as arrhythmia and hemolytic disorders. Because these comorbidities might have stopped us from giving hydroxychloroquine to the affected patients. For a further discussion, it has to be stated that although some small and initial studies showed early promise for hydroxychloroquine, more recent and better designed studies have refuted any survival benefit from the drug in COVID-19 patients (Gautret et al. 2020; Geleris et al. 2020). Moreover, a Randomized Clinical Trial (RCT) was stopped prematurely because patients in the higher hydroxychloroquine dosage arm were showing serious side effects and a higher mortality rate (Borba et al. 2020). Another recent RCT showed no post-exposure prophylactic role for the drug in people with household or occupational exposure to confirmed COVID-19 patients (Boulware et al. 2020).

\section{Complications}

ARDS was observed as the most common adverse event among hospitalized patients. Based on the current 
evidence, the SARS-CoV-2 infection ranging from mild to severe respiratory disease, in $17-29 \%$ of cases can progress to ARDS (Kanne et al. 2020). As a common observation in the patients, infection with SARS-CoV-2 was correlated with an increase in several pro-inflammatory mediators, provoking a cytokine storm, which may have prominent roles in the pathophysiology of cardiac and arrhythmic complications, as well as respiratory involvement (Rizzo et al. 2020). Furthermore, the medications used to control COVID-19 do bear a high risk of causing the arrhythmia. Long-term use of hydroxychloroquine is well-reported to improve the depolarization time-span and the Purkinje fiber refractory period. Therefore, it potentially results in atrioventricular nodal and, or His-Purkinje system failure (Joyce et al. 2013). It has also been documented that frequent use of Levofloxacin and Azithromycin may lead to severe arrhythmias (Rao et al. 2014).

Another troubling issue that we faced, has been the challenging diagnosis of cardiac cases and initially differentiating them from COVID-19 cases; this is due to the interfering fact that the clinical presentations of SARS-CoV-2 cases like weakness, coughing, and dyspnea, are very similar to that of heart failure patients.

There are limitations in the present study. The incidence of patients with cancer-involved and subsequent related problems was more prevalent in our results in part due to the referral nature of the hospital (i.e., a referral center of malignancy and cardiovascular diseases). This may induce differences in manifestations and prognosis in comparison to the more general population of hospitalized COVID-19 patients. Also, we could not state our viewpoints sharply regarding the mortality rate of COVID-19 patients, because by the time the study was coming to an end, many patients were in hand, whose conditions were yet to be determined.

In conclusion, we have demonstrated that the careful and precise consideration of patients' medical history and underlying conditions plays a huge role in the proper management of COVID-19. Notably, increased age, higher MBI, drug history taking of statins, as well as laboratory findings such as elevated creatinine and CRP, along with decreased lymphocyte count, and reduced magnesium levels upon admission in COVID-19 patients could make practitioners alert to the possibility of poor prognosis. It is of the essence that further studies about this strange virus should be conducted to shed more light on the matter.

\section{Acknowledgments}

The authors would like to take this opportunity to express their gratitude to Clinical Research Development Unit (CRDU) of Shahid Modarres Hospital, Shahid Beheshti University of Medical Sciences, Tehran, Iran, and also the nursing personnel of Shahid Modarres Hospital, for all the assistance, cooperation and help that they provided, throughout the research.

\section{Conflict of Interest}

The authors declare no conflict of interest.

\section{References}

Abdi, M. (2020) Coronavirus disease 2019 (COVID-19) outbreak in Iran: actions and problems. Infect. Control Hosp. Epidemiol., 41, 754-755.

Alraddadi, B.M., Watson, J.T., Almarashi, A., Abedi, G.R., Turkistani, A., Sadran, M., Housa, A., Almazroa, M.A., Alraihan, N., Banjar, A., Albalawi, E., Alhindi, H., Choudhry, A.J., Meiman, J.G., Paczkowski, M., et al. (2016) Risk factors for primary middle east respiratory syndrome coronavirus illness in humans, Saudi Arabia, 2014. Emerg. Infect. Dis., 22, 49-55.

Borba, M.G.S., Val, F.F.A., Sampaio, V.S., Alexandre, M.A.A., Melo, G.C., Brito, M., Mourão, M.P.G., Brito-Sousa, J.D., Baía-da-Silva, D., Guerra, M.V.F., Hajjar, L.A., Pinto, R.C., Balieiro, A.A.S., Pacheco, A.G.F., Santos, J.D.O. Jr., et al. (2020) Effect of high vs low doses of chloroquine diphosphate as adjunctive therapy for patients hospitalized with severe acute respiratory syndrome coronavirus 2 (SARSCoV-2) infection: a randomized clinical trial. JAMA Netw. Open, 3, e208857.

Boulware, D.R., Pullen, M.F., Bangdiwala, A.S., Pastick, K.A., Lofgren, S.M., Okafor, E.C., Skipper, C.P., Nascene, A.A., Nicol, M.R., Abassi, M., Engen, N.W., Cheng, M.P., LaBar, D., Lother, S.A., MacKenzie, L.J., et al. (2020) A randomized trial of hydroxychloroquine as postexposure prophylaxis for Covid-19. N. Engl. J. Med., 383, 517-525.

Casey, K., Iteen, A., Nicolini, R. \& Auten, J. (2020) COVID-19 pneumonia with hemoptysis: acute segmental pulmonary emboli associated with novel coronavirus infection. Am. J. Emerg. Med., 38, 1544. e1-3.

Conti, P. \& Younes, A. (2020) Coronavirus COV-19/SARS-CoV-2 affects women less than men: clinical response to viral infection. J. Biol. Regul. Homeost. Agents, 34, 339-343.

Cucinotta, D. \& Vanelli, M. (2020) WHO declares COVID-19 a pandemic. Acta Biomed., 91, 157-160.

D’Antiga, L. (2020) Coronaviruses and immunosuppressed patients: the facts during the third epidemic. Liver Transpl., 26, 832-834.

Dai, X. (2020) ABO blood group predisposes to COVID-19 severity and cardiovascular diseases. Eur. J. Prev. Cardiol., 2047487320922370.

de Wit, E., van Doremalen, N., Falzarano, D. \& Munster, V.J. (2016) SARS and MERS: recent insights into emerging coronaviruses. Nat. Rev. Microbiol., 14, 523-534.

Duwe, S. (2017) Influenza viruses-antiviral therapy and resistance. GMS Infect. Dis., 5, Doc04.

Gautret, P., Lagier, J.C., Parola, P., Hoang, V.T., Meddeb, L., Mailhe, M., Doudier, B., Courjon, J., Giordanengo, V., Vieira, V.E., Tissot Dupont, H., Honoré, S., Colson, P., Chabrière, E., La Scola, B., et al. (2020) Hydroxychloroquine and azithromycin as a treatment of COVID-19: results of an open-label non-randomized clinical trial. Int. J. Antimicrob. Agents, 105949.

Geleris, J., Sun, Y., Platt, J., Zucker, J., Baldwin, M., Hripcsak, G., Labella, A., Manson, D.K., Kubin, C., Barr, R.G., Sobieszczyk, M.E. \& Schluger, N.W. (2020) Observational study of hydroxychloroquine in hospitalized patients with Covid-19. N. Engl. J. Med., 382, 2411-2418.

Goldwasser, P. \& Feldman, J. (1997) Association of serum albumin and mortality risk. J. Clin. Epidemiol., 50, 693-703.

Grasselli, G., Zangrillo, A., Zanella, A., Antonelli, M., Cabrini, L., Castelli, A., Cereda, D., Coluccello, A., Foti, G., Fumagalli, R., Iotti, G., Latronico, N., Lorini, L., Merler, S., Natalini, G., 
et al. (2020) Baseline characteristics and outcomes of 1591 patients infected with SARS-CoV-2 admitted to ICUs of the Lombardy Region, Italy. JAMA, 323, 1574-1581.

Guan, W.J., Ni, Z.Y., Hu, Y., Liang, W.H., Ou, C.Q., He, J.X., Liu, L., Shan, H., Lei, C.L., Hui, D.S.C., Du, B., Li, L.J., Zeng, G., Yuen, K.Y., Chen, R.C., et al. (2020) Clinical characteristics of coronavirus disease 2019 in China. N. Engl. J. Med., 382, 1708-1720.

Helfant, R.H. (1986) Hypokalemia and arrhythmias. Am. J. Med., 80, 13-22.

Holshue, M.L., DeBolt, C., Lindquist, S., Lofy, K.H., Wiesman, J., Bruce, H., Spitters, C., Ericson, K., Wilkerson, S., Tural, A., Diaz, G., Cohn, A., Fox, L., Patel, A., Gerber, S.I., et al. (2020) First case of 2019 Novel Coronavirus in the United States. N. Engl. J. Med., 382, 929-936.

Hong, K.H., Choi, J.P., Hong, S.H., Lee, J., Kwon, J.S., Kim, S.M., Park, S.Y., Rhee, J.Y., Kim, B.N., Choi, H.J., Shin, E.C., Pai, H., Park, S.H. \& Kim, S.H. (2018) Predictors of mortality in Middle East respiratory syndrome (MERS). Thorax, 73, 286-289.

Huang, C., Wang, Y., Li, X., Ren, L., Zhao, J., Hu, Y., Zhang, L., Fan, G., Xu, J., Gu, X., Cheng, Z., Yu, T., Xia, J., Wei, Y., Wu, W., et al. (2020) Clinical features of patients infected with 2019 novel coronavirus in Wuhan, China. Lancet, 395, 497-506.

Hui, D.S., Azhar, E.I., Kim, Y.J., Memish, Z.A., Oh, M.D. \& Zumla, A. (2018) Middle East respiratory syndrome coronavirus: risk factors and determinants of primary, household, and nosocomial transmission. Lancet Infect. Dis., 18, e217-e227.

Hulme, K.D., Gallo, L.A. \& Short, K.R. (2017) Influenza virus and glycemic variability in diabetes: a killer combination? Front. Microbiol., 8, 861.

Jia, N., Feng, D., Fang, L.Q., Richardus, J.H., Han, X.N., Cao, W.C. \& de Vlas, S.J. (2009) Case fatality of SARS in mainland China and associated risk factors. Trop. Med. Int. Health, 14 Suppl 1, 21-27.

Jin, J.M., Bai, P., He, W., Wu, F., Liu, X.F., Han, D.M., Liu, S. \& Yang, J.K. (2020) Gender differences in patients with COVID-19: focus on severity and mortality. Front. Public Health, 8, 152.

Joyce, E., Fabre, A. \& Mahon, N. (2013) Hydroxychloroquine cardiotoxicity presenting as a rapidly evolving biventricular cardiomyopathy: key diagnostic features and literature review. Eur. Heart J. Acute Cardiovasc. Care, 2, 77-83.

Kanne, J.P., Little, B.P., Chung, J.H., Elicker, B.M. \& Ketai, L.H. (2020) Essentials for radiologists on COVID-19: an updateradiology scientific expert panel. Radiology, 296, E113-E114.

Li, Q., Guan, X., Wu, P., Wang, X., Zhou, L., Tong, Y., Ren, R., Leung, K.S.M., Lau, E.H.Y., Wong, J.Y., Xing, X., Xiang, N., Wu, Y., Li, C., Chen, Q., et al. (2020) Early transmission dynamics in Wuhan, China, of novel coronavirus-infected pneumonia. N. Engl. J. Med., 382, 1199-1207.

Lippi, G. \& Henry, B.M. (2020) Active smoking is not associated with severity of coronavirus disease 2019 (COVID-19). Eur. J. Intern. Med., 75, 107-108.

Mackenzie, J.S. \& Smith, D.W. (2020) COVID-19: a novel zoonotic disease caused by a coronavirus from China: what we know and what we don't. Microbiol. Aust., MA20013.

Milbrandt, E.B., Reade, M.C., Lee, M., Shook, S.L., Angus, D.C., Kong, L., Carter, M., Yealy, D.M., Kellum, J.A. \& Gen, I. M.S.I. (2009) Prevalence and significance of coagulation abnormalities in community-acquired pneumonia. Mol. Med., 15, 438-445.

Oostra, M., de Haan, C.A., de Groot, R.J. \& Rottier, P.J. (2006) Glycosylation of the severe acute respiratory syndrome coronavirus triple-spanning membrane proteins $3 \mathrm{a}$ and $\mathrm{M}$. $J$. Virol., 80, 2326-2336.

Plein, L.M. \& Rittner, H.L. (2018) Opioids and the immune system - friend or foe. Br. J. Pharmacol., 175, 2717-2725.

Rao, G.A., Mann, J.R., Shoaibi, A., Bennett, C.L., Nahhas, G., Sutton, S.S., Jacob, S. \& Strayer, S.M. (2014) Azithromycin and levofloxacin use and increased risk of cardiac arrhythmia and death. Ann. Fam. Med., 12, 121-127.

Rizzo, P., Vieceli Dalla Sega, F., Fortini, F., Marracino, L., Rapezzi, C. \& Ferrari, R. (2020) COVID-19 in the heart and the lungs: could we "Notch" the inflammatory storm? Basic Res. Cardiol., 115, 31.

Rodelo, J.R., De la Rosa, G., Valencia, M.L., Ospina, S., Arango, C.M., Gómez, C.I., García, A., Nuñez, E. \& Jaimes, F.A. (2012) D-dimer is a significant prognostic factor in patients with suspected infection and sepsis. Am. J. Emerg. Med., 30, 1991-1999.

Rubeiz, G.J., Thill-Baharozian, M., Hardie, D. \& Carlson, R.W. (1993) Association of hypomagnesemia and mortality in acutely ill medical patients. Crit. Care Med., 21, 203-209.

Salimi, V., Hennus, M.P., Mokhtari-Azad, T., Shokri, F., Janssen, R., Hodemaekers, H.M., Rygiel, T.P., Coenjaerts, F.E., Meyaard, L. \& Bont, L. (2013) Opioid receptors control viral replication in the airways. Crit. Care Med., 41, 205-214.

Sarnak, M.J. \& Jaber, B.L. (2001) Pulmonary infectious mortality among patients with end-stage renal disease. Chest, 120, 1883-1887.

Shahverdi, E., Moghaddam, M., Talebian, A. \& Abolghasemi, H. (2016) Distribution of blood groups in the Iranian general population. Immunohematology, 32, 135-139.

Simonnet, A., Chetboun, M., Poissy, J., Raverdy, V., Noulette, J., Duhamel, A., Labreuche, J., Mathieu, D., Pattou, F. \& Jourdain, M.; LICORN and the Lille COVID-19 and Obesity study group (2020) High prevalence of obesity in severe acute respiratory syndrome coronavirus-2 (SARS-CoV-2) requiring invasive mechanical ventilation. Obesity (Silver Spring), 28, 1195-1199.

Syedmoradi, L., Ghasemi, A., Zahediasl, S. \& Azizi, F. (2011) Prevalence of hypo- and hypermagnesemia in an Iranian urban population. Ann. Hum. Biol., 38, 150-155.

Wang, H. \& Zhang, L. (2020) Risk of COVID-19 for patients with cancer. Lancet Oncol., 21, e181.

World Health Organization (WHO) (2020a) Clinical management of severe acute respiratory infection (SARI) when COVID-19 disease is suspected: interim guidance, 13 March 2020. https://apps.who.int/iris/handle/10665/331446 [Accessed: 5 June 2020].

World Health Organization (WHO) (2020b) Coronavirus disease 2019 (COVID-19): situation report, 98. https://www.who.int/docs/default-source/coronaviruse/situationreports/20200427-sitrep-98-covid-19.pdf?sfvrsn=90323472 4 [Accessed: 5 June 2020].

Yan, C.H., Faraji, F., Prajapati, D.P., Boone, C.E. \& DeConde, A.S. (2020) Association of chemosensory dysfunction and COVID-19 in patients presenting with influenza-like symptoms. Int. Forum Allergy Rhinol., 10, 806-813.

Yang, J.K., Feng, Y., Yuan, M.Y., Yuan, S.Y., Fu, H.J., Wu, B.Y., Sun, G.Z., Yang, G.R., Zhang, X.L., Wang, L., Xu, X., Xu, X.P. \& Chan, J.C. (2006) Plasma glucose levels and diabetes are independent predictors for mortality and morbidity in patients with SARS. Diabet. Med., 23, 623-628.

Yang, P. \& Wang, X. (2020) COVID-19: a new challenge for human beings. Cell. Mol. Immunol., 17, 555-557.

Yuan, S. (2015) Statins may decrease the fatality rate of Middle East respiratory syndrome infection. $\mathrm{mBio}, \mathbf{6}, \mathrm{e} 01120$.

Zhou, F., Yu, T., Du, R., Fan, G., Liu, Y., Liu, Z., Xiang, J., Wang, Y., Song, B., Gu, X., Guan, L., Wei, Y., Li, H., Wu, X., Xu, J., et al. (2020) Clinical course and risk factors for mortality of adult inpatients with COVID-19 in Wuhan, China: a retrospective cohort study. Lancet, 395, 1054-1062. 